\title{
EFFECT OF PRISCOL ON THE PULMONARY CIRCULATION IN COR PULMONALE
}

\author{
BY \\ J. WIDIMSKÝ, J. KASALICKÝ, A. VALACH, R. DEJDAR, Z. VYSLOUŽIL, \\ AND M. LUKES* \\ From the Institute for Cardiovascular Research (Dir. Prof. Dr. K. Weber), Prague-Krč, Czechoslovakia \\ Received October 23, 1959
}

Pulmonary hypertension in chronic pulmonary disease is due mainly to the impairment of the pulmonary vascular bed. It is still doubtful, however, whether neuro-humoral factors also participate in the genesis of this hypertension. Because of the difficulties of the methods that have to be used in the study of this problem, little is known about the autonomous regulation of the lesser circulation in man. Lately there have been some attempts to extend our knowledge in this field by pharmacological investigations of the lesser circulation.

Most of the authors have dealt with pulmonary hypertension in congenital or acquired heart disease. Several substances have been employed as e.g. TEAB (Davies et al., 1954; Scott et al., 1955), hexamethonium (Gilmore et al., 1952; Judson et al., 1954; Wade et al., 1956), theophyllinethylendiamin (Storstein et al., 1958), regitin (Storstein et al., 1957), serpasil (Halmágyi et al., 1957), acetylcholin (Harris, 1957; Söderholm and Werkö, 1959; Wood, 1957), procain (Gottsegen et al., 1959) and priscol (Braun et al., 1957; Dresdale et al., 1951; Dresdale et al., 1954; Rudolph et al., 1958).

The genesis of hypertension in congenital and acquired heart disease, however, differs from that of hypertension in cor pulmonale. Little attention has been paid to pulmonary hypertension in cor pulmonale so that the number of studies concerned with the pharmacology of this problem is small. The only substances to be used in sufficiently large groups of subjects with cor pulmonale have been TEAB (Fowler et al., 1950) and hexamethonium (Malamos et al., 1957; Sancetta, 1955). However, results are difficult to assess since the doses of these substances used lowered systemic blood pressure. An attempt was therefore made to affect pulmonary hypertension in cor pulmonale pharmacologically by employing a substance that would lower pulmonary arterial blood pressure without substantially affecting systemic blood pressure. Since it was found (Widimský et al., 1959) that priscol fulfils these requirements, the effect of this drug upon patients with cor pulmonale has been investigated in greater detail.

Methods. Fifteen patients with pulmonary disease, 11 of these with pulmonary hypertension at rest, within an age range of 21-68 years were investigated by catheterization of the pulmonary circulation. One day before catheterization the following premedication was applied: phenobarbital 0.06 g. natr. bromati 0.6 g., chinidini sulphur 0.2 g., and on the day of catheterization phenobarbital $0.03 \mathrm{~g}$., natrii bromati $0.3 \mathrm{~g}$., and chinidini sulphur $0.1 \mathrm{~g}$. were administered. Catheterization was performed in the usual manner, always in the morning. The catheter was introduced into the pulmonary artery and a Cournand needle was introduced into the femoral artery. Pulmonary arterial pressure, systemic blood pressure (Riva-Rocci, right arm), and pulse rate were measured. Pressures in the lesser circulation were measured with an electromanometer of Elema type and recorded with an Elema-42 mingograph, and the mean pressure was determined by electrical integration. Mean systemic blood pressure was estimated by adding one-third of the pressure amplitude to the diastolic pressure. Pulmonary arterial blood pressure, pulse rate, and systemic blood pressure were measured at 5-minute intervals for a total period of 20-30 minutes.

* With the technical assistance of E. Blahutová. 
At the end of this period of 20-30 minutes, oxygen consumption was measured. The expired air was collected for 3-5 minutes in Douglas bags and analysed with a Zeiss interferometer. During breathing into these bags pressures were again measured and simultaneously blood samples were drawn from the pulmonary and femoral arteries. Arterial oxygen saturation was estimated with a Brinkman hæmoreflectometer (Kipp-Delft). Blood hæmoglobin was done photometrically. Cardiac output was determined by the direct Fick method. In 9 patients pulmonary capillary venous pressure also was recorded.

After this initial period a dose of 10-30 mg. of priscol dissolved in $10 \mathrm{ml}$. of saline was injected into the pulmonary artery through a catheter. Pulmonary arterial pressure, systemic blood pressure, and pulse rate were recorded immediately after injection and $1,3,5,10,15$, and 20 minutes thereafter. Oxygen consumption was measured in the 8-12-minute period in 6 patients. Since, in accordance with reports (Rudolph et al., 1958) priscol application was without effect on oxygen consumption in these 6 subjects, oxygen consumption in the remaining 9 patients was measured only prior to priscol injection. Blood samples were taken 5, 10, and 15 minutes following injection. In 9 patients the measurement of pulmonary capillary venous pressure was repeated in the tenth minute.

\section{RESULTS}

Table I shows the clinical data of the individual patients. Table II presents the results. All values in the latter table refer to the 10th minute following injection, when in most of the patients pulmonary arterial pressure changes were greatest. In 12 patients the mean pulmonary arterial pressure decreased and in the remaining three practically no change was observed: no increase in pulmonary arterial pressure was observed. In 9 of the 15 patients the fall in pressure exceeded 10 per cent of the initial level, and in 5 priscol caused a return to normal of the pulmonary arterial pressure. Pulmonary capillary venous pressure, as far as it was measured, showed in the majority of cases a small rise, so that there was a distinct decrease in pressure gradient across the lesser circulation. Respiratory changes in pulmonary blood pressure were unaffected by priscol. Mean systemic blood pressure remained practically unchanged (11 cases): it increased in three cases and decreased only in one.

TABLE I

Clinical Data of Individual Patients

\begin{tabular}{c|c|l|c}
\hline Case No. & Age and sex & Diagnosis & $\begin{array}{c}\text { Priscol: dose } \\
\text { in mg. }\end{array}$ \\
\hline 1 & $40 \mathrm{~F}$ & Chronic disseminated pulm. tuberculosis, emphysema & 10 \\
2 & $57 \mathrm{M}$ & Chronic fibrocaseous pulm. tuberculosis & 10 \\
3 & $63 \mathrm{M}$ & Chronic fibrocaseous pulm. tuberculosis & 10 \\
4 & $59 \mathrm{M}$ & Emphysema, chronic bronchitis & 20 \\
5 & $54 \mathrm{M}$ & Emphysema, chronic bronchitis & 20 \\
6 & $57 \mathrm{M}$ & Chronic fibrocaseous pulm. tuberculosis & 10 \\
7 & $52 \mathrm{~F}$ & Chronic fibrocaseous pulm. tuberculosis & 20 \\
8 & $55 \mathrm{M}$ & Chronic fibrocaseous pulm. tub., multiple pulm. cysts & 20 \\
9 & $21 \mathrm{~F}$ & Pulmonary fibrosis & 30 \\
10 & $68 \mathrm{M}$ & Chronic fibrocaseous pulm. tub., right thoracoplasty C. $4-7$ & 20 \\
11 & $39 \mathrm{M}$ & Thrombo-embolic pulm. disease, pulm. fibrosis & 20 \\
12 & $68 \mathrm{M}$ & Chronic pulm. fibrocaseous tuberculosis & 30 \\
13 & $60 \mathrm{M}$ & Chronic fibrocaseous pulm. tub., bullous emphysema & 30 \\
14 & $59 \mathrm{M}$ & Silicosis & 20 \\
15 & $56 \mathrm{M}$ & Silicosis & 20 \\
\hline
\end{tabular}

Cardiac output increased in 10 patients, remained substantially unchanged in 4 , and decreased only in 1 patient. A decrease in total pulmonary resistance by more than 10 per cent was observed in 13 patients, and in 2 it was practically unchanged. Pulmonary arteriolar resistance decreased in all patients by more than 30 per cent of the initial value. 


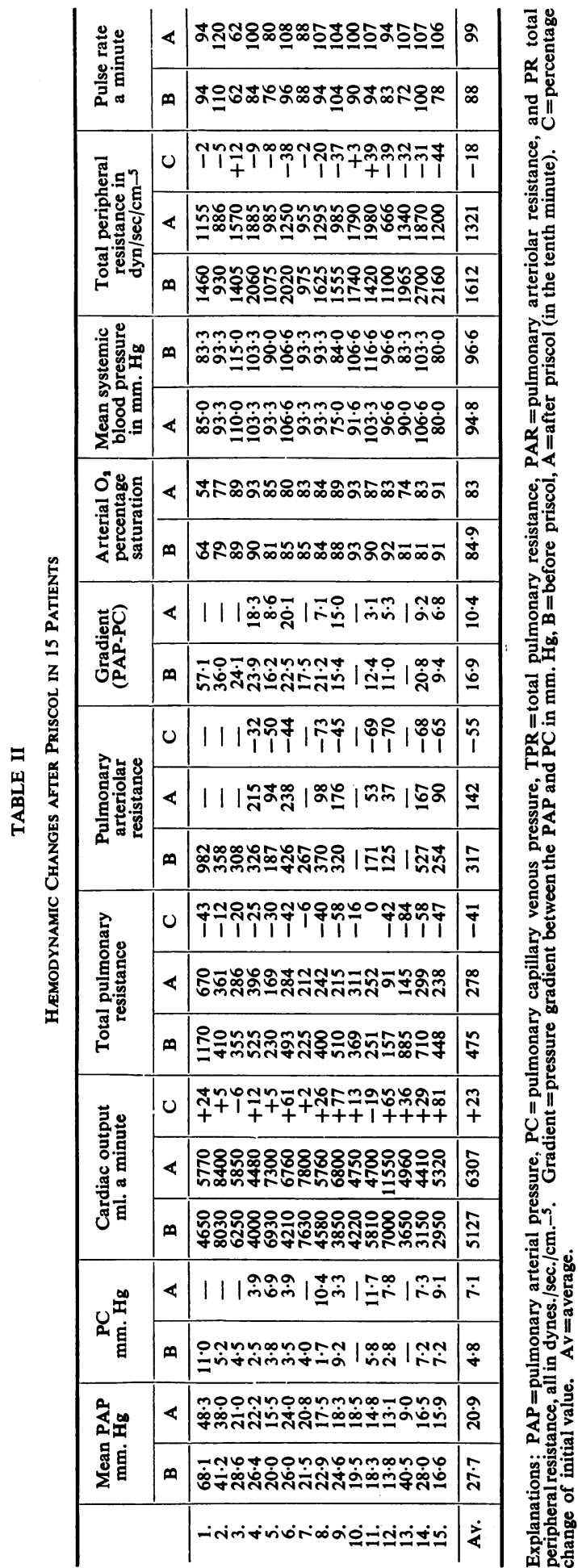


Total peripheral resistance in the systemic circulation decreased in 8 patients, remained substantially unchanged in 5 , and increased in 2 patients. Table II shows also the changes of the average values and Fig. 1 presents percentage average changes.

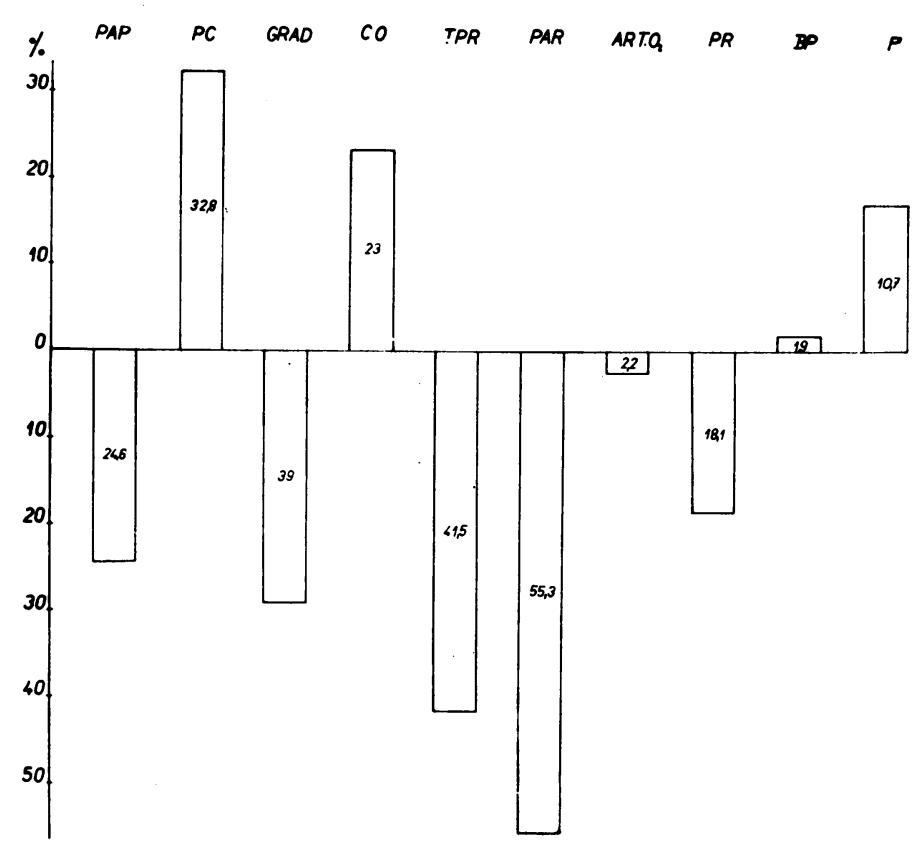

Fig. 1.-Average changes in several hæmodynamic factors after priscol, expressed as the percentage change of the initial values, increases above the line and decreases below it. Abbreviations as in notes to Table II, and $\mathrm{PR}=$ peripheral systemic resistance, and $\mathrm{BP}=$ blood pressure.

The decreases in pulmonary arterial pressure and in total pulmonary and pulmonary arteriolar resistance were related to the corresponding initial values (Fig. 2, 3, 4). The higher the initial levels, the greater the decrease that could be expected. Right heart work was substantially unchanged: 6 times it decreased, 5 times it was unchanged, and 4 times it increased.

Arterial blood oxygen saturation was changed by more than 2 per cent of saturation in 7 patients, in 5 of whom it increased, but in 8 patients the changes were less than 2 per cent. Pulse rate in 10 patients was increased by more than 6 strokes a minute and in 5 patients no change was observed. Drops in pulmonary arterial blood pressure, and in total pulmonary and pulmonary vascular resistances were also found at an elevated or unchanged total peripheral resistance (Table II): however, in cases where the latter had decreased, the former falls were greater but not statistically significant.

\section{Discussion}

Priscol injection into the lesser circulation caused the following changes in most patients with pulmonary disease: a decrease in pulmonary arterial blood pressure, a decrease in pulmonary vascular resistance, and a rise in cardiac output. A decrease in pulmonary vascular resistance at a simultaneously increased blood flow has, according to numerous authors, to be assessed with care. Experimental work on healthy dogs showed that the pulmonary bed is dilated by an increased blood flow so that there is a decrease in the calculated pulmonary resistance (Borst et al., 1956; Edwards, 1951; and Williams, 1954). 
DECREASE OF THE MEAN PAP

AFTER PRISCOL

in $\mathrm{mm} \mathrm{Hg}$

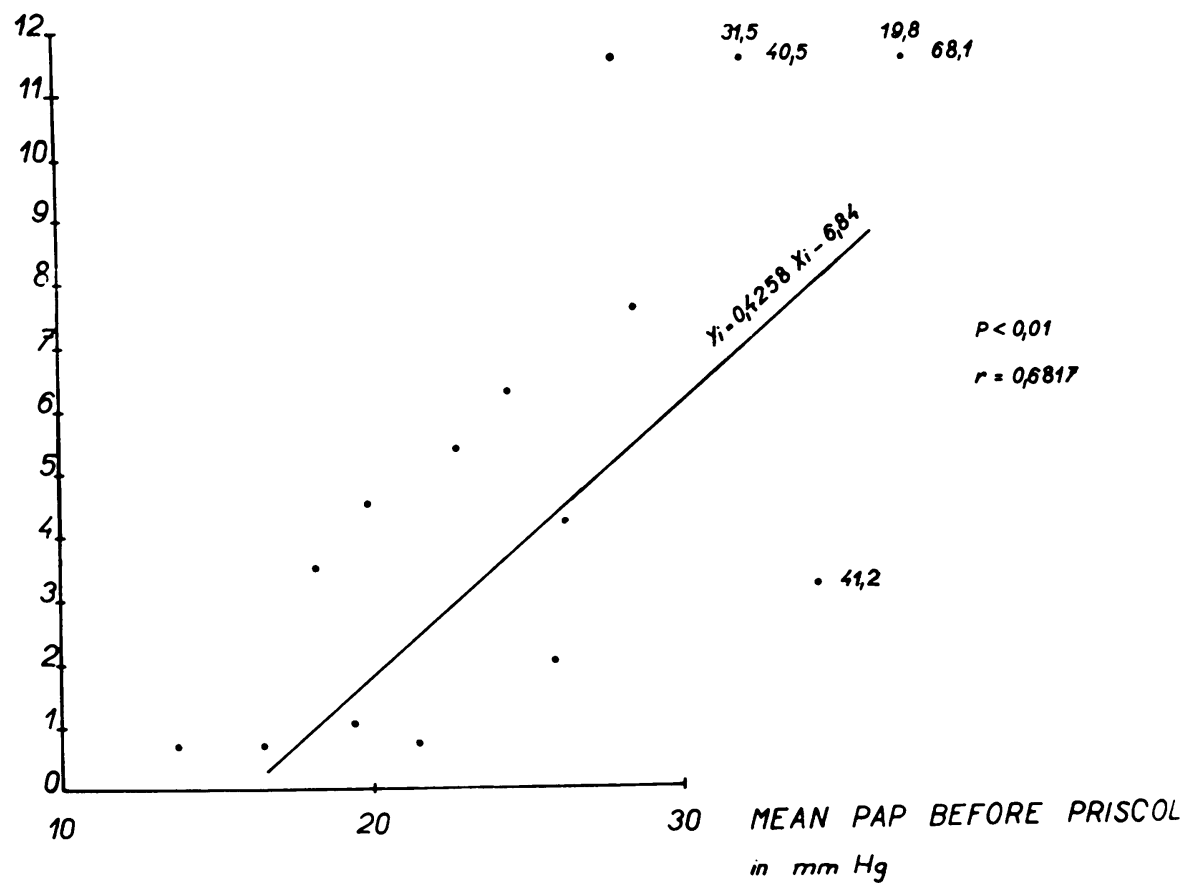

Fig. 2.-Decrease of the mean pulmonary arterial pressure after priscol.

DECREASE OF TPR

AFTER PRISCOL

${ }^{500} 1170{ }^{740} \cdot 885$

in $\mathrm{dy} / \mathrm{soc} / \mathrm{cm}^{-3}$

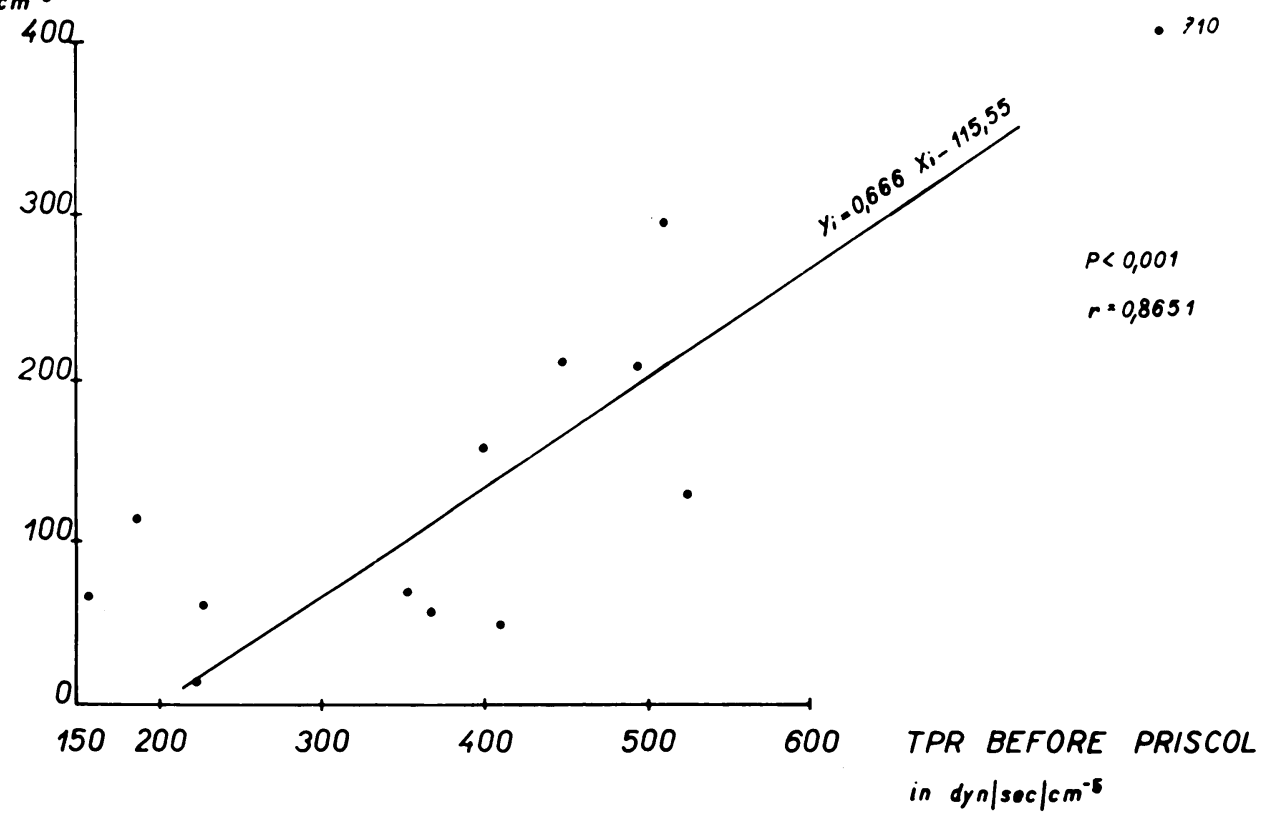

FIG. 3.-Decrease of the total pulmonary resistance (TPR) after priscol. 


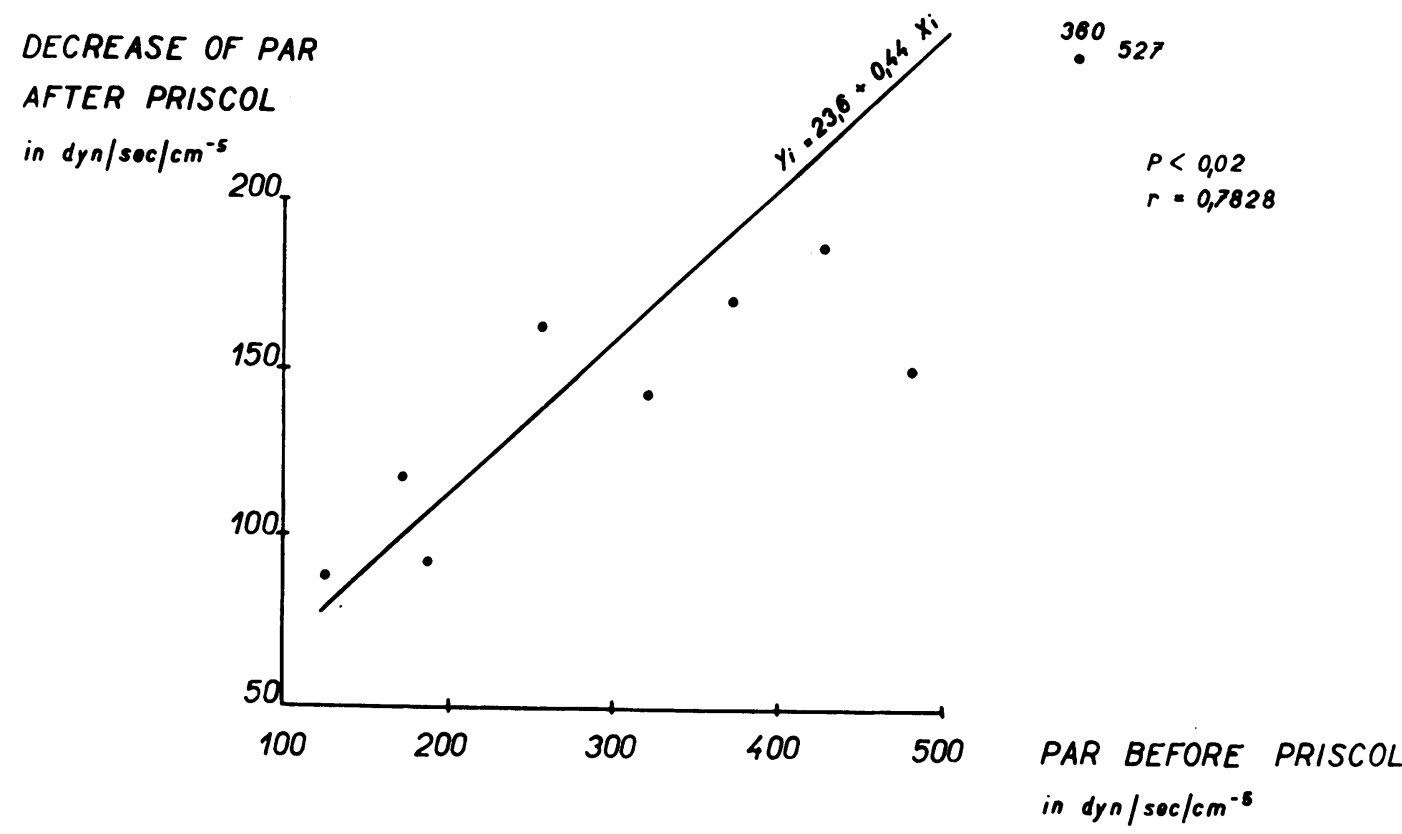

Fig. 4.-Decrease of the pulmonary arteriolar resistance (PAR) after priscol.

Edwards (1951) compares the lung with a highly elastic bag, the resistance of which changes inversely with blood flow. Williams (1954) also found an increased resistance at low intravascular pressures, which he interpreted as a narrowing or closing of the vessels in some part of the pulmonary vascular bed. In a complex distensible low pressure system, such as the pulmonary vascular bed in healthy dogs, vascular lumen is minimal and some vessels are probably closed (Borst et al., 1956; Williams, 1954). In the period of great blood flow more capillaries are open and it is possible that their opening is stimulated by a raised pulmonary arterial blood pressure (Borst et al., 1956): changes in intravascular pressure due to changes in blood flow thus make the interpretation of resistance values difficult. These relations have been established in the lungs of healthy dogs, but it is highly doubtful whether they apply in a pulmonary vascular bed that is anatomically considerably limited, as in cor pulmonale. Moreover, the factors mentioned above act immediately, whereas the maximal effect on pulmonary arterial blood pressure was established in the tenth minute.

It is, however, significant that decreases in pulmonary arterial blood pressure and in pulmonary vascular resistance after priscol could be found also in parients whose cardiac outputs were practically unaffected or even decreased (patients $2,3,5,7$ and 11).

In the observations of the above-mentioned authors there was always a rise in pulmonary arterial blood pressure at increased blood flows. In an anatomically impaired pulmonary vascular bed in man also, there were always rises of pulmonary arterial blood pressure at increased blood flows, e.g. during muscular work (Söderholm, 1957): this, however, was usually larger than in healthy subjects. In our observations priscol caused a fall in pulmonary arterial blood pressure regardless of increased blood flow. Some authors (Cournand, 1950 and 1957, and Judson et al., 1954) object that the fall in pulmonary arterial blood pressure that follows some drugs in men might be caused by a shift of blood from the lesser circulation to the systemic circulation at a simultaneous fall of systemic peripheral resistance. Against this mechanism the following arguments may be put forward: (1) the decreases in pulmonary vascular resistance and in total pulmonary resistance and pulmonary arterial blood pressure could be found also in 7 patients where there was no substantial change in peripheral 
resistance or where the latter had even increased (patients $2,3,4,5,7,10,11$ ); and (2) the fall in pulmonary arterial blood pressure combined with an increase in pulmonary capillary venous pressure cannot be explained by a decrease in the pulmonary blood volume (Harris, 1957).

Nor can bronchial constriction account for the pressure changes in the lesser circulation. This is borne out by the fact that priscol is without effect on ventilation and oxygen consumption (Rudolph et al., 1958) and that, according to our observations, respiratory variations in intravascular pressure in the pulmonary circulation remained unchanged.

In contrast to reported data (Braun et al., 1957; Dresdale et al., 1954; Söderholm and Werkö, 1959; Storstein et al., 1958) a fall in arterial oxygen saturation was not met with as frequently as has been reported after the use of hypotensive drugs. Only in 5 patients was there a significant fall in arterial oxygen saturation and this might be due to a shift in ventilation-perfusion ratio, in the sense of increased blood flow through the poorly ventilated areas (Dresdale, 1951 and 1954; Söderholm and Werkö, 1959).

The hæmodynamic reaction observed in the lesser circulation may be explained, we believe, purely by a dilatation of the pulmonary vascular bed due to priscol either by a blockade of sympathetic hyperactivity and/or by a local effect on the pulmonary bed. The extent of this hæmodynamic reaction depends on the initial level. The greater the initial pressure values in the pulmonary artery, the greater was the decrease that could be expected. This is in agreement with the findings of other authors on the pharmacology of pulmonary hypertension in mitral stenosis (Braun et al., 1957; Gottsegen et al., 1959). These findings are, according to Harris (1957), accounted for by the fact that only the hypertrophied muscles of the pulmonary vessels that are found in pulmonary hypertension of various origins are capable of significant relaxation and contraction. Patel (1958), however, advances a different explanation. The finding of a higher increase in pulmonary vascular resistance due to nor-adrenalin infusion in healthy subjects than in patients with impaired pulmonary vascular resistance is explained by a decreased contractive ability of the abnormal pulmonary bed. Patel's data, however, may also be interpreted in just the opposite way, i.e. by assuming that contracted vessels are less affected by nor-adrenalin.

Priscol application thus demonstrates the functional factor of hypertension in cor pulmonale. The therapeutic effect of priscol in cor pulmonale is doubtful since the changes in the pulmonary arterial pressure observed are merely of a maximum duration of 10-15 minutes. The possible significance of priscol in differentiating between anatomical and functional components in cor pulmonale cannot be excluded. Here it has to be borne in mind that in 5 patients $(5,8,9,13$, and 14) there was even a temporary return to normal of pulmonary arterial blood pressure. These observations show that the functional factor may be decisive in the genesis of pulmonary hypertension as has already been suggested by some post-mortem findings (Dresdale et al., 1951). The data presented show again that pharmacotherapy of pulmonary hypertension in cor pulmonale may become justified though a suitable substance has still to be found.

\section{SUMmaRY}

The injection of priscol (10-30 mg.) into the pulmonary artery was investigated in 15 subjects with pulmonary disease, 11 of whom had chronic cor pulmonale. Significant decreases of pulmonary arterial pressure, pulmonary vascular resistance, and total pulmonary resistance occurred in most of them. Systemic arterial pressure remained unchanged. The response to priscol was related to the initial level of pulmonary arterial pressure and total pulmonary and pulmonary vascular resistance. Arterial oxygen saturation and systemic peripheral resistance did not show any consistent changes. It is possible that the decrease of pulmonary arterial pressure was due to vasodilatation in the periphery of the pulmonary arterial tree.

\section{REFERENCES}

Borst, H. G., McGregor, M., Whittenberger, J. L., and Berglund, E. (1956). Circulat. Res., 4, 393. Braun, K., Izak, G., and Rosenberg, S. Z. (1957). Brit. Heart J., 19, 217. 
Cournand, A. (1950). Circulation, 2, 641.

(1957). Amer. Heart J., 54, 172.

Davies, L. G., Goodwin, J. F., and Van Leuven, B. D. (1954). Brit. Heart J., 16, 440.

Dresdale, D. T., Schultz, M., and Michtom, R. J. (1951). Amer. J. Med., 11, 686.

-, Michtom, R. J., and Schultz, M. (1954). Bull. New York Acad. Med., 30, 195.

Edwards, W. S. (1951). Amer. J. Physiol., 167, 756.

Fowler, N. O., Westcott, R. N., Hauenstein, V. D., Scott, R. C., and McGuire, J. (1950). J. clin. Invest., 29, 1387.

Gilmore, H. R., Kopelman, H., McMichael, J., and Milne, I. G. (1952). Lancet, 2, 898.

Gottsegen, G., Romoda, T., and Matheides, P. (1959). Acta Cardiol., 14, 149.

Halmágyi, D., Felkai, B., Czipott, Z., and Kovács, G. (1957). Brit. Heart J., 19, 375.

Harris, P. (1957). Brit. Heart J., 19, 272.

Judson, W. E., Hollander, W., and Arrowwood, J. G. (1954). J. clin. Invest., 33, 946.

Malamos, B., Moulopoulos, S., Dimakis, D., Primikiris, D., and Kyriakopoulos, A. (1957). Z. Kreislauff., 46, 681.

Patel, D. J., Lange, R. L., and Hecht, H. H. (1958). Circulation, 18, 19.

Rudolph, A. M., Paul, M. H., Sommer, L. S., and Nadas, A. S. (1958). Amer. Heart J., 55, 424.

Sancetta, S. M. (1955). Amer. Heart J., 49, 501.

Scott, R. C., Kaplan, J., and Stiles, W. J. (1955). Amer. Heart J., 50, 720.

Shepherd, J. T., Semler, H. J., and Helmholz, H. F. (1958). Circulation, 18, 781.

Söderholm, B. (1957). Scand. J. clin. lab. Invest., 9, 26.

-, and Werkö, L. (1959). Brit. Heart J., 21, 1 .

Storstein, O., Elgvin, T., Helle, I., and Sebelien, J. (1957). Scand. J. clin. lab. Invest., 9, 150.

, Helle, I., and Rokseth, R. (1958). Amer. Heart J., 55, 781.

Wade, E. G., Mackinnon, J., and Vickers, C. F. H. (1956). Brit. Heart J., 18, 458.

Widimský, J., Valach, A., Dejdar, R., Fejfar, Z., Bergmann, K., Vysloužil, Z., and Lukeš, M. (1959). Cardiologia (Basel), 35, 154.

Williams, M. H. Jr. (1954). Amer. J. Physiol., 179, 243.

Wood, P., Bestermann, E. M., Towers, M. K., and McIlroy, M. B. (1957). Brit. Heart J., 19, 279. 